\title{
A comparative analysis of different pitching rates on castle lager beer flavour stability: A case study of delta lagers manufacturing company Harare, Zimbabwe
}

\author{
Perkins Muredzi, Chiridza Lynette Tendai, Dinga N. Moyo, Clive Winini \\ Department of Food Processing Technology, School of Industrial Sciences and Technology, Harare Institute of Technology, Ganges Rd, \\ Belvedere Box BE 277, Harare, Zimbabwe
}

\author{
Email address: \\ pmuredzi@hit.ac.zw (P. Muredzi), lynchiridza@yahoo.com (C. L. Tendai), dmoyo@hit.ac.zw (D. N. Moyo), \\ cwinini@hit.ac.zw (C. Winini)
}

\section{To cite this article:}

Perkins Muredzi, Chiridza Lynette Tendai, Dinga N. Moyo, Clive Winini. A Comparative Analysis of Different Pitching Rates on Castle Lager Beer Flavour Stability: A Case Study of Delta Lagers Manufacturing Company Harare, Zimbabwe. International Journal of Nutrition and Food Sciences. Special Issue: Optimizing Quality and Food Process Assessment.

Vol. 3, No. 6-1, 2014, pp. 22-29. doi: 10.11648/j.ijnfs.s.2014030601.14

\begin{abstract}
Beer stability is a critical quality parameter and there is vast amount of research that has been done in attempt to understand and optimise it. The research study was incited by the result of low lag time (potential to resist staling) and high T150 (degree of staling) in one of the main stream brands at the beer processing firm, which caused the beer to stale much faster than normal. The research focused on the flavour stability aspect of beer stability and different methods of analysis were employed to investigate the effect of different pitching rates on products of yeast metabolism in-turn flavour stability. Results revealed that beer fermented with a low pitching rate had a high amount of sulphur dioxide which meant the Lag Time was also high due to sulphur dioxide exerting anti-oxidant properties which prevented oxidation of beer for longer periods than beer fermented with a high pitching rate. The results also revealed that there is no significant difference in these beers regards sensory analysis following analysis using the t-test.
\end{abstract}

Keywords: Lag Time, Flavour Stability, T150 (Degree of Staling), Ribes, Strecker Degradation

\section{Introduction}

Recent research has indicated that beer can be a source of specific antioxidants which help reduce the risk of cardiovascular disease and lower the occurrence of certain types of cancers [26]. Appearance and taste (colour, hue, brightness, foam quality, glass fullness and flavor) are the sensory attributes on which consumers judge the acceptability of the product and they use them to critically evaluate every glass of beer they drink. The major thrust in beer quality lies upon the beers' foam stability, colloidal stability and most importantly flavour stability [4]. Beer flavour stability is of paramount importance since it has the potential to detrimentally affect foam and colloidal stability. A flavour stable beer is fresh, has a clean taste, a pleasurable aroma, and a crisp, pleasing bitterness that is thirst quenching.

Flavour changes that occur during beer maturation play a critical role in the product quality and brand identity of beer. Successful brands that strive for maximum flavour stability are generally well received and recognized for such attributes by consumers. While it is preferred that flavour improves during the maturation process, formation of undesirable flavours inevitably occurs during beer storage. More problematic is that occurrence of aged-flavours varies from one beer style to another, with lager beer seeming especially sensitive. Of the many chemicals involved in beer flavour modification, a few key groups have been identified: di-ketones, sulphur compounds, aldehydes and volatile fatty acids [3]. In general, beer aging results in decreased bitter taste, increased sweet taste and increased caramel, ribes (black currant), and toffee-like aromas. Carbonyl compounds such as trans-2-nonenal (cardboard aroma) form during beer storage from the oxidation of fatty 
acids and have been attributed to aged-beer flavour due to their very low flavour thresholds. The trade complaints of Castle Lager brand since 2008 are mostly viable mould, a cloudy product, the product not reaching its standard shelf life, various taste complaints including bad odour, sweet beer, off taste and 'cardboard' taste.

The major thrust of this research was to improve Castle lager beer flavour stability by reducing the amount of dissolved oxygen and free radical species in the product.

Sensory changes during storage of beer

Currently, the main quality problem of beer is the change of its chemical composition during storage, which alters the sensory properties. A variety of flavours may arise, depending on the beer type and storage conditions. In contrast to some wines, beer aging is usually considered negative for flavour quality. The main focus on beer aging has been the study of the cardboard-flavoured component (E)-2-nonenal and its formation by lipid oxidation. Other stale flavours are less described, but may be at least as important for the overall sensory impression of aged beer. Their origin has been increasingly investigated in recent years.

Dalgliesh [7] described sensory changes during beer storage, but the Dalgliesh plot (Fig 1) is a generalization of the sensory evolution during beer storage and is not applicable to every beer. The graph shows the general taste acceptance by consumers immediately after it has been packaged. Over time, the bitterness, fruitiness and drinkability of the beer decline while at the same time taste characteristics such as papery, cardboard-like and sweetness all increase to a less satisfying product. Freshness is linked with drinkability. The fresher the beer, the more drinkable it is.

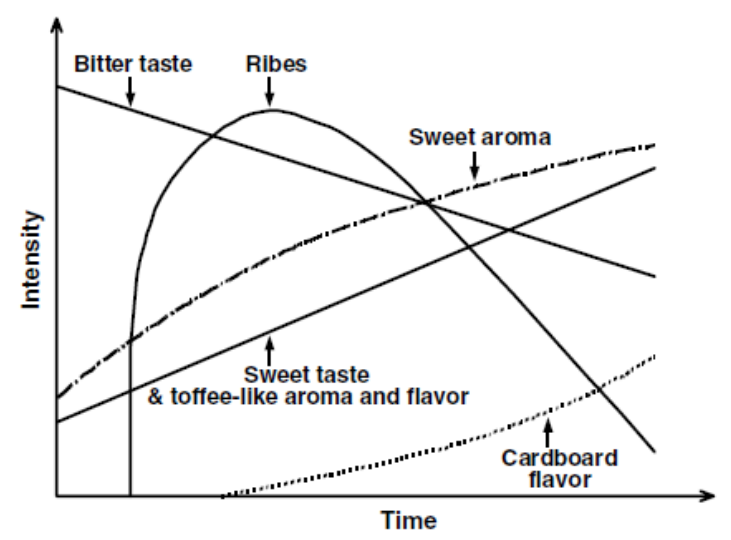

Figure 1. Sensory changes during beer aging (Dalgliesh, 1977).

\section{Methodology}

\subsection{Experimental Research Design}

\subsubsection{Research Population}

In this research the population comprised:

Population A: Normal beer fermented with a yeast pitching rate of $0.8 \mathrm{~kg} / \mathrm{hl}$

Population B: Beer fermented with a yeast pitching rate of $0.9 \mathrm{~kg} / \mathrm{hl}$

Population C: Beer fermented with a yeast pitching rate of $0.7 \mathrm{~kg} / \mathrm{hl}$

Population D: Delta Lagers taste panel

\subsubsection{Sampling}

The sample size consisted of three samples each from Castle Lager pitched at $0.8 \mathrm{~kg} / \mathrm{hl}$ : Sample A, $0.9 \mathrm{~kg} / \mathrm{hl}$ : Sample B, 0.7kg: Sample C and the one pitched at $0.8 \mathrm{~kg} / \mathrm{hl}$ which served as the control (as this is the pitching rate normally used at Delta Beverages for the Castle Lager brand). Samples were purposively sampled in one batch, these beer samples have similar characteristics that require analysis for example alcohol concentration, hence required the same sampling technique and sample size. Samples were taken at day ten of fermentation vessel stage, at racking, at day six of storage vessel stage, bright beer tank and at packaging ex-filler and ex-pasteuriser for all laboratory analysis.

\subsection{Data Collection Techniques}

\subsubsection{The Research Tools}

Laboratory analysis was carried out to ascertain comparative state of the quality of product. The researchers employed the use of a trained panel of 10 individuals, consisting of professional beer tasters.

\subsubsection{Experimental Work}

Analysis was done on sample A, B and C to test parameters which include sulphur dioxide, diacetyl, bitterness units, lag time and T150 values.

\subsection{Experimental Data Collection Procedures}

\subsubsection{Yeast Pitching Rates}

The pitching rate that is currently being used for Castle Lager brewing at Delta Beverages is $0.8 \mathrm{~kg} / \mathrm{hl}$. In this research, all parameters remained the same with the exception of sample B $(0.9 \mathrm{~kg} / \mathrm{hl}$ pitching rate $)$ and sample $\mathrm{C}(0.7 \mathrm{~kg} / \mathrm{hl}$ pitching rate). After wort cooling the respective yeast pitching rates were added to respective batches. The yeast pitching rate simply refers to the amount of yeast that is added to cooled wort. Fermentation profile was monitored so was the flavour stability profile at each stage ferment vessel (FV), storage vessel (SV), bright beer tank (BBT) and packaged beer.

\subsubsection{Determination of the Dissolved Oxygen in the Beer}

This analysis was done three times during the filling of the bright beer tank. A dissolved oxygen meter (Orbisphere 3100) was used for this analysis to measure the amount of dissolved oxygen within a sample. It was rinsed through with carbonated water (MUL) whose reading was also taken. A pint was pre-attemperated to $20^{\circ} \mathrm{C}$, after which the cap was opened and placed on the analyser to run, the reading was then recorded. 


\subsubsection{Sulphur Dioxide Determination}

Tubes were chilled to $0^{\circ} \mathrm{C}$ in ice water prior to sampling of the packaged sample. The flasks were rinsed with ethanol and dried using air currents before sampling. A clean dry centrifuge tube was inserted into a beaker containing crushed ice. A sample coil was connected to the tank sample cock and the line was thoroughly flushed. Slowly the centrifuge tube was filled to the brim with sample and immediately capped. The sample was incubated at $4^{\circ} \mathrm{C}$. Sample was centrifuged at $2000 \mathrm{~g}$ for 10 minutes. In removing the sample from the centrifuge caution was maintained so as not to disturb the sediment. The centrifuged sample was returned to the beaker containing crushed ice. Mercury stabilising solution and sulphuric acid were added to two labelled flasks (free and total $\mathrm{SO}_{2}$ ). Prepared samples were put into each flask and stoppered. For the blank, starch indicator was added as well as iodine solution drop-wise until a blue colour persisted. The samples were diluted with purified water and stoppered. $25 \mathrm{ml}$ of each sample was pipetted in a corresponding volumetric flask and colour reagent (p-rosaline) was added to each flask. Water was added to each flask and stoppered and placed in a water bath at $25^{\circ} \mathrm{C}$ for exactly 30 minutes. The intensity of colour was determined spectrophotometrically (UV-1800, Shimadzu) against purified water at a wavelength of $550 \mathrm{~nm}$ and recorded.

\subsubsection{Bitterness Units (BU) Analysis}

Prepared samples were pipetted into a BU tube and hydrochloric acid and iso-octane was added to the tube. Glass beads were put into the tube and the BU tube was stoppered and placed on the BU shaker for 15 minutes. The tubes were centrifuged using a centrifuge for 3 minutes and the absorbance of ultra violet (UV) was measured using a spectrophotometer (UV-1800, Shimadzu) at 275nm against iso-octane and recorded.

\subsubsection{Determination of Vicinal Di-Ketones I. E. Diacetyl by Gas Chromatography}

The Gas Chromatograph (Hewlett Packard, Agilent Technologies, 1200 Infinity Series) was used to determine diacetyl and acetaldehyde. $200 \mathrm{ml}$ sample was measured; it was then filtered through a filter paper with $1 \mathrm{~g}$ kieselguhr. The conical flask collecting the sample had 1 or 2 drops of antifoam added. From the filtered sample $10 \mathrm{ml}$ were pipetted into an HPLC (High Performance Liquid Chromatograph) vile The sample was attemperated to $0^{\circ} \mathrm{C}$ for 20-30 minutes before analysis.

\subsubsection{Determination of ESR Value}

The estimation of the hydroxyl radical and anti-oxidant values was performed using a Bruker Biospin, an Electronic Spin Resonance instrument (model ESG 0395), equipped with an auto-sampler, a heating block and a Gibson auto-pump system for continuous sampling. The ELBA Software version 3.20 with incorporated Lag-Time analysis software, version 1.09 was used for data processing.

\subsubsection{Preparation of 4-Hydroxy 2, 2, 6, 6 Tetramethyl Piperidin-1-Oxy (Tempo)}

Calibration Solutions: $34 \mathrm{mg}+/-0.1 \mathrm{mg}$ of tempo was weighed out into clean amber assay vials, $10 \mathrm{ml}$ of deionised water was added and mixed thoroughly till dissolved. Absorbance was measured at 429nm. Dilutions were calculated (with water) required to get 3.0 and $4.0 \mu \mathrm{M}$ final concentration of tempo. $100 \mathrm{ml}$ of each concentration was made and $8 \mathrm{ml}$ aliquots frozen in assay vials. One sample of 3 and $4 \mu \mathrm{M}$ tempo each by standing the vials in room temperature water. Before starting the T150 or lag time assays, the two tempo concentrations were run. For each assay run in, the 3 and $4 \mu \mathrm{M}$ stock solutions were inserted together with the other wort, green beer and beer samples. This allowed the condition of the peristaltic pump tubing to be monitored throughout the lag time and T150 assays. Lag Time and T150 Assays: N-tert-Butyl- $\alpha-$ Phenylnitrone (PBN) Stock Solution-Out of $678 \mathrm{mg} \gamma 0.1 \mathrm{mg}$ of PBN was weighed into acid-washed amber assay vial. Using a Gilson P1000, $750 \mu$ of ethanol was added to the PBN and vortexed at very low speed until completely dissolved. Using a Gilson P1000, 7501 deionized water was added and mixed again at very low speed.

Lag Time Assay: Out of $7 \mathrm{~g} \mu 0.01 \mathrm{~g}$ of wort, green beer and beer was weighed into acid-washed amber assay vial weighed samples should be run within 30 minutes of preparation. $280 \mu$ of PBN was added with a Hamilton syringe to the pre-weighed sample, vortexed briefly, and added to the heating block. The timer was started when the first sample was added to the heating block and activated the ELBA software. PBN was added to each successive vial every 2 minutes thereafter immediately cleaned the Hamilton syringe with $50 \%$ ethanol to prevent the PBN crystals from blocking the needle 8 samples were assayed per run with at least one standard.

T150 Assay: $3 \mathrm{~g} \mu 0.01 \mathrm{~g}$ of sample were incubated with $1201 \mu \mathrm{PBN}$ for $150 \mathrm{~min}$ at $60^{\circ} \mathrm{C}$ and one reading was taken at this time. PBN was added to each successive sample and inserted into the heating block every 2 minutes. Once the escan was activated, the auto sampler will rinse and then go back to the starting position. Once start was activated, the software counted down to $150 \mathrm{~min}$ and started on its own once the time had elapsed.

\subsubsection{Sensory Analysis of Beer}

Beer flavour evaluations and ageing score assessments were carried out by a trained panel of beer tasters. For aging score assessments sample beer was tasted at week one, week four, week eight and week twelve and the degree of staling assessment in aged beer was evaluated by ten experienced tasters. Flavour evaluation was used to describe flavour profile and sensory defects of the beer, the ten tasters were asked to fill in a flavour score card with 45 attributes. The Delta beer ageing score was used to judge the degree of beer ageing. The panel was asked to taste the three beer samples, and emphasis was made on the brand flavour which includes alcohol, sweet, bitter, hoppy, fruity, 
floral and sour. They were asked to fill a brand profile score card with eight attributes.

\subsubsection{Hypothesis Testing Using the Student'S t-Test for Two Independent Samples}

The t-Test was used to test the hypotheses about the differences between the samples of different pitching rates that were analysed in the laboratory. Berenson (2002), states that a t-Test is used to acquire differences between sample means, regardless of their direction of difference. The t-Test was applied to lag time, T150 and the sensory evaluation. The test statistic was done using the t-test at 5\% significance level.

H01: There is no significant difference in the Lag Time (potential to resist staling) of Castle Lager fermented with lower/higher pitching rates and normal Castle Lager.

\section{Results and Discussion}

\section{Lag Time and T150}

Table 1 below shows the Lag Time and T150 of the control taken at different brewing stages.

Table 2 below shows the Lag Time and T150 of beer pitched with a high pitching rate measured at different brewing stages.

Table 3 below shows the Lag Time and T150 of beer pitched with a low pitch rate measured at different brewing stages.

Table 1. Control Pitching Rate

\begin{tabular}{lll}
\hline Sample Identity & Lag time (mins) & T150 \\
\hline Ferment Vessel & 60 & 68792 \\
Storage Vessel & 59 & 58269 \\
BBT & 59 & 88672 \\
Packaged Ex-Filler & 52 & 70322 \\
Packaged Ex-Pasteuriser & 50 & 66923 \\
\hline
\end{tabular}

Table 2. High Pitching Rate

\begin{tabular}{lll}
\hline Sample Identity & Lag time (mins) & T150 \\
\hline Ferment Vessel & 68 & 60608 \\
Storage Vessel & 68 & 54102 \\
BBT & 67 & 52136 \\
Packaged Ex-Filler & 64 & 43870 \\
Packaged Ex-Pasteuriser & 61 & 56787 \\
\hline
\end{tabular}

Table 3. Low Pitching Rate

\begin{tabular}{lll}
\hline Sample Identity & Lag time (mins) & T150 \\
\hline Ferment Vessel & 84 & 43567 \\
Storage Vessel & 76 & 52178 \\
BBT & 74 & 34970 \\
Packaged Ex-Filler & 72 & 43208 \\
Packaged Ex-Pasteuriser & 70 & 45230 \\
\hline
\end{tabular}

The above graph illustrates the difference of Lag Times measured at different brewing stages for beers pitched with different pitching rates.

Sensory Evaluation

Table 4 shows taste scores for different ages for beer pitched at different pitch rates.
Table 4. Sample Scores.

\begin{tabular}{lllll}
\hline & \multicolumn{4}{l}{ Sample Scores out of $\mathbf{1 0}$ for respective ages } \\
\hline Sample Identity & 1 week & 4 weeks & 8 weeks & 12 weeks \\
\hline Control & 9.0 & 8.2 & 7.1 & 6.1 \\
High Pitch & 8.9 & 7.3 & 6.9 & 5.8 \\
Low Pitch & 9.0 & 8.5 & 7.7 & 7.1 \\
\hline
\end{tabular}

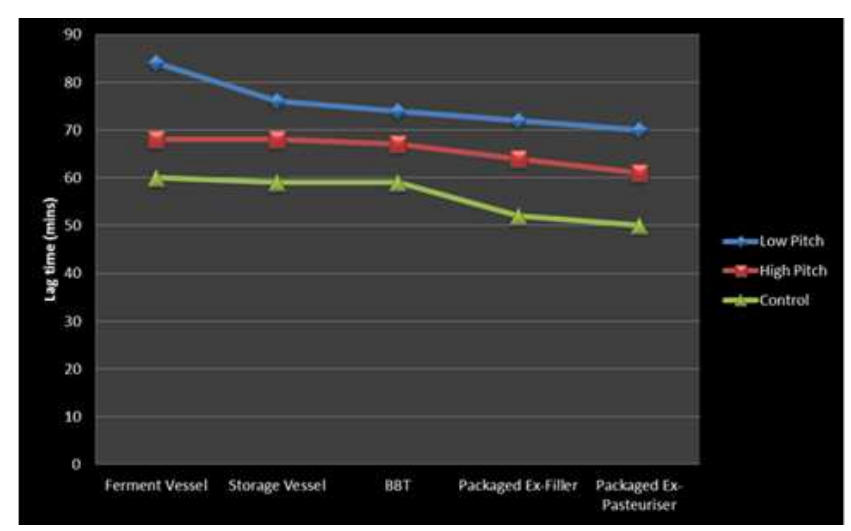

Figure 2. Graph of Lag Time of beer samples

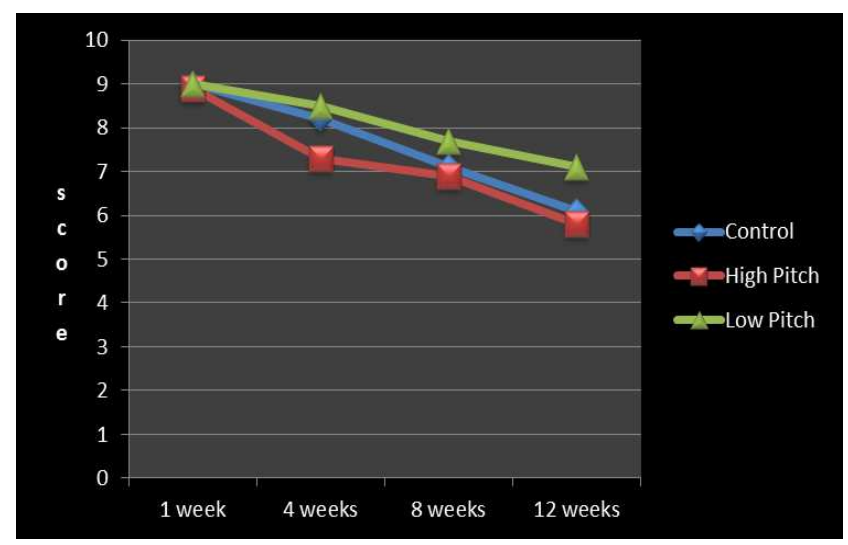

Figure 3. Graph showing sensory evaluation scores at different ages

The graph above illustrates the aging of beer according to 10 trained Delta tasters. The results show that the score of beer (and hence the acceptability) decreased with time. By 12 weeks the beer sample pitched with low yeast rate had the highest score and that of high pitching rate had the lowest score.

Hypothesis testing using the student's t-Test for Two Independent samples

The calculation in showed that:

High pitch rate and control Tcal $=13.2$

Low pitch rate and control Tcal $=11.2$

Tcrit $=3.13$

Decision: Reject $\mathrm{H} 01$

H02: There is no significant difference in the T150 (degree of staling) of Castle Lager beer fermented with lower/higher pitching rates and normal Castle Lager

High pitch rate and control Tcal $=15.4$

Low pitch rate and control Tcal $=14.7$

Tcrit $=3.13$ 
Decision: Reject $\mathrm{H} 02$

H03: There is no significant difference in sensory evaluation of Castle Lager beer fermented with different pitching rates and normal Castle Lager
High pitch rate and control Tcal $=0.045$

Low pitch rate and control Tcal $=0.076$

Tcrit $=2.23$

Decision: Accept $\mathrm{H} 03$

Table 5. Flavour Wheel Key

\begin{tabular}{|c|c|c|c|c|c|c|c|c|c|}
\hline \multicolumn{10}{|c|}{ Flavour Wheel Key } \\
\hline \multicolumn{10}{|c|}{ Character } \\
\hline 1 & Mouldy & 10 & Sulphitic & 19 & Malty & 28 & Ethyl-hexanoate & 37 & Mouth Coating \\
\hline 2 & Leathery & 11 & Oily & 20 & Worty & 29 & Ethyl- acetate & 38 & Alkaline \\
\hline 3 & Papery & 12 & Rancid & 21 & Resinous & 30 & Alcoholic & 39 & Bitter \\
\hline 4 & Catty & 13 & Diacetyl & 22 & Nutty & 31 & Body & 40 & Salty \\
\hline 5 & Oxidised/stale & 14 & Fatty Acid & 23 & Grassy & 32 & Warming & 41 & Sweet \\
\hline 6 & Yeast & 15 & Phenolic & 24 & Hoppy & 33 & Carbonated & 42 & Sour \\
\hline 7 & Chlorophenol & 16 & Caramel & 25 & Floral & 34 & Powdery & 43 & Acetic \\
\hline 8 & Fluidic & 17 & Burnt & 26 & Acetaldehyde & 35 & Astringent & 44 & Acidic \\
\hline 9 & Sulphitic & 18 & Grainy & 27 & Iso-amylacetate & 36 & Metallic & 45 & Light Struck \\
\hline
\end{tabular}

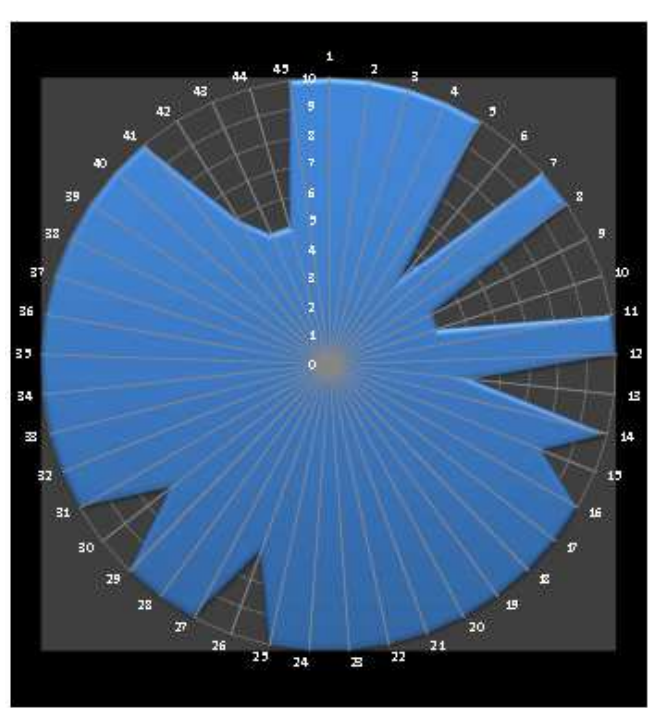

Figure 4. Flavour Wheel for High Pitch

The flavour wheel above in Figure 4 also shows a degree of flavour inconsistency. The major flavour defects are chlorophenol, yeasty, fluidic, Sulphitic, Sulphury, sweet, acetic and acidic from the flavour wheel key in table 5 .

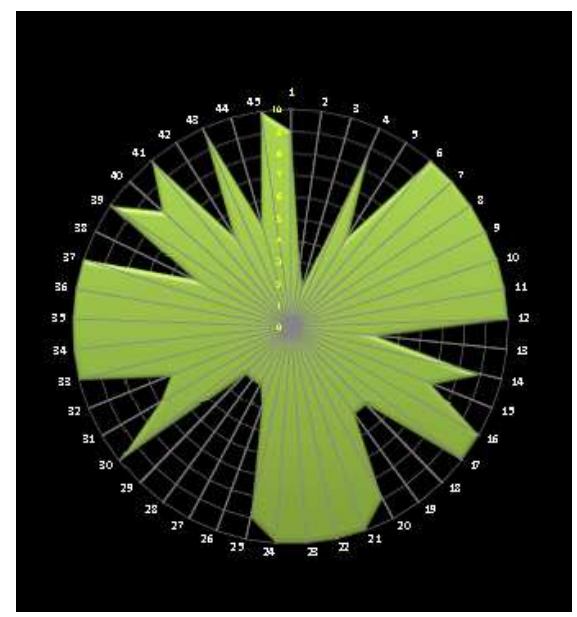

Figure 5. Flavour Wheel for Low Pitch
From the flavour wheel in Table 5 ,Figure 4 and figure 5, it is clear that there is no consistency in the overall flavour. The major off-flavour defects being found to be diacetyl, leathery, papery, catty and oxidised from the flavour wheel key in Table 5.

\section{Discussion}

The various experiments conducted were all focused on attaining information on improving flavour stability of Castle Lager. The comparison of different results from the different pitching rates provided an insight on the capability of pitching rates towards improving the flavour stability of beer.

Low pitching rates yielded a higher level of $\mathrm{SO}_{2}$ than the higher pitching rate and the control. Sulphur dioxide is produced in small amounts during the brewing process usually at concentrations of $<10 \mathrm{ppm}$. According to Hardwick (1994), low pitching rates make the amount of oxygen utilized to make sterols for new cells lower and overall growth is lowered. Insufficient growth will led to slower and perhaps stuck fermentations. Poor yeast growth therefore led to high $\mathrm{SO}_{2}$ concentrations. Yeast growth patterns had an influence on the flavour of beer by changing the proportions of volatile flavour compounds. Sulphur dioxide plays an important role in the flavour and stability of lager beers.

Bitterness units in high pitching rate were lower than the rest of the samples and this was due to the uptake of bitter substances through the yeast cell wall and increased foaming during fermentation. Bitterness of the beer is an important quality parameter. It is caused by the alpha-acids of hops which are isomerised during wort boiling.

Diacetyl, which is a vicinal diketone, can cause a buttery off-flavour above its threshold and it is one of the most important by-products in alcoholic fermentation as it decreases the sensory properties of the final product. In the experiments carried out, low pitching rate had the highest diacetyl level of $28.7 \mathrm{ppb}$ at Day 10 of fermentation and at $15.6 \mathrm{ppb}$ at packaging compared to $22.7 \mathrm{ppb}$ and $11.1 \mathrm{ppb}$ for high pitching rate at Day 10 of fermentation and packaging 
respectively. There was a significant drop in the diacetyl concentration from fermentation day 10 to packaging. This phenomenon was probably owing to higher production of $\alpha$-acetolactate during day 1 to day 9 , due to longer fermentation time the diacetyl concentration dropped as a result of complete reduction of diacetyl [33] . Lower diacetyl content in the green beer led to shorter maturation time.

Formation of diacetyl is also influenced by the spectrum and total concentration of amino acids present in the wort. In particular the concentration of valine is significant. Diacetyl is formed by an extracellular oxidative decarboxylation of $\alpha$-acetolactate and valine is a strong inhibitor of the enzyme acetohydroxy synthase which catalyses the formation of $\alpha$-acetolactate [10] . In high pitching rates, the concentration of valine is high and this enzyme is inhibited and accordingly diacetyl formation is very low. In low pitching rates the concentration of valine is low thus there is high formation of the enzyme thus the result of high diacetyl levels. Subsequently, yeast cells assimilate and reduce diacetyl to the flavour inactive compounds acetoin ad 2,3-butanediol. The ability of lager strains to assimilate and reduce diacetyl is influenced by physiological conditions. Yeast of anaerobic repressed physiology, as in the case of cropped pitching yeast, has a lower ability to assimilate and reduce exogenous diacetyl and this could be the case for the reduction of diacetyl for Day 10 to Packaging. Pitching at high levels decreased the $\mathrm{pH}$ and the formation of diacetyl was reduced.

Lag time indicates the potential to resist staling. A higher lag time implies the presence of more anti-oxidants which allows the beer to resist staling for longer. Thus the higher the Lag Time the better the flavour stability. The lag time in the low pitching rate was found to be higher than that of the high pitching rate and the control. This was because there were high levels of $\mathrm{SO}_{2}$ produced during fermentation in beer pitched with a lower rate and it acted as an antioxidant. $\mathrm{SO}_{2}$ has three main roles in beer, firstly it reacts with carbonyl compounds to form alpha-hydroxysulphonates and these are not flavour active and thus increase the threshold of carbonyl compounds responsible for the stale flavour (Bamforth, 2011). Also sulphur dioxide inhibits oxidative reactions. The ESR lag time provides an estimate of the ability of a particular beer, at a particular point in it shelf life, to prevent the reactions that will further oxidize the beer and this is probably why low pitch rate beer has a higher lag time than other samples. $\mathrm{SO}_{2}$ also exerts antimicrobial properties at high concentrations.

Sulphur dioxide in beer as highlighted before acts as an antioxidant, these antioxidant properties are seen to have a positive relationship with T150 (degree of staling) and lag time (potential to resist staling). The results from Figure 3 and Figure 4 illustrate the potential to resist staling (lag time) and the degree of staling (T150) and respectively. The control sample showed very high T150 results while showing very low lag times. The two results together show that there was low concentration of antioxidants hence the beer could not resist staling for long hence the lower lag times. Comparing the results with that of sulphur dioxide in Figure 3 indicate that a relationship exists between sulphur dioxide and T150 (degree of staling) and lag time (potential to resist staling). As sulphur dioxide increases the T150 (degree of staling) decreases and the lag time (potential to resist staling) increases. This is a result of the antioxidant properties found in soluble sulphur dioxide [1] .

According to the different scores given by the trained tasters, there was a difference in the beer brewed using different pitching rates. In as much as the lag time determines how a beer will stay fresh to a particular time, it is the sensory evaluation that really matters as use of different pitching rates might bring out some flavours that might help prevent staling but change the Castle Lager profile. In the sensory evaluation, lower pitching rates were found to result in higher intensities of the overall aroma, hoppy and fruity aroma notes in the finished beer. And this was because the high BU levels that were observed in the experiment results. With respect to the aroma compound, the concentration of isobutanol and isoamyl alcohol increased with higher pitching rate. In general, the concentration of higher alcohols is positively influenced by the pitching rate.

The flavour wheel in Figure 4 and Figure 5 was presented to facilitate the location of terms within a system. The wheel was meant as an aid to classify odours and tastes . Figure 4 illustrates the flavour wheel of the sample with pitching rate of $0.7 \mathrm{~kg} / \mathrm{hl}$ which has flavour defects such as papery which is due to the oxidation. According to Bamforth [4] it can be said that all beers are susceptible to flavour degradation due to aging. Thus flavour active compounds such as furfural, trans-2-nonenal, acetaldehyde and other oxidative products of normal beer flavour constituents are responsible for contributing cardboard, papery or strawberry like off flavours to beer. The other flavour notes include iso-amyl acetate, ethyl-hexanoate and ethyl acetate. These are estery flavours that are desirable because they impart a fruity or floral characteristic that is generated from yeast. However, these flavours failed to reach the correct threshold that could be detected by the trained panel.

Beer pitched with a rate of $0.8 \mathrm{~kg} / \mathrm{hl}$ had flavour defects which include the acidic, yeasty, sulphitic and sulphury note. There are numerous sulphur containing compounds in finished beer [4], the factors that contribute to sulphur notes are poor kettle boil, low oxygenation of the wort, yeast strain, slow fermentation, bacterial contamination and exposure of bottle beer to light. As illustrated by figure 11, beer fermented with a pitching rate of $0.9 \mathrm{~kg} / \mathrm{hl}$ almost had the same flavour defects .

The flavour profile is a descriptive sensory procedure, it describes and evaluates in a corresponding manner the aroma and taste of the product. The test uses a highly trained panel that systematically characterise a beer based upon the amplitude, which is a rating of the degree of blend and fullness in the aroma and flavour as a whole. Secondly 
it focuses on the identification of the individual components of aroma and flavour. Thirdly it looks at the strength or intensity at which these components appear. Fourthly it looks at the order in which they appear and lastly it gives a description of the aftertaste one minute after swallowing. The control sample experienced inconsistencies in fact that they off on the floral and sour note. Beer brewed with a pitching rate of $0.9 \mathrm{~kg} / \mathrm{hl}$ was a bit sour yeasty and the sweet note was a bit low. Beer fermented with a pitching rate of $0.7 \mathrm{~kg} / \mathrm{hl}$ suffered on the sweet note for it was a bit low.

\section{Conclusion}

Different pitching rates do have an effect on the Lag Time and T150 thus flavour stability of beer. Low pitching rates gave a higher Lag Time and a lower T150 but had flavour defects such as sweet flavours that might not be desirable to people. On the other hand, higher pitching rates gave a slightly lower Lag Time compared to that given by pitching with a low rate and the T150 is quite high.

\section{References}

[1] Aron, P. and. Shellhammer, T., 2010. A Discussion of Polyphenols in Beer Physical and Flavour Stability, J. Inst. Brew., 116(4), 369-380.

[2] ASBC, 1992. Methods of analysis, 8th Edition, The American Society of Brewing Chemists., 565p

[3] Bamforth, C.W., 1999. The science and understanding of the flavour stability of beer: a critical assessment. Brauwelt International, 98-110

[4] Bamforth, C., 2011. 125th Anniversary Review: The NonBiological Instability of Beer, J. Inst. Brew., 117(4), 488497.

[5] Bright, D., Stewart, G. G., \& Patino, H., 1999, A novel assay for antioxidant potential of specialty malts. Journal of the American Society of Brewing Chemists, 57, 133-137.

[6] Clapperton, J.F., 1976. Ribes flavour in beer. Journal of the Institute of Brewing, 82, 175-176

[7] Dalgliesh, C.E., 1977. Flavour stability. Proceedings of the European Brewery Convention Congress, 623-659.

[8] De Cooman, L., Aerts, G., Overmeire, H., \& De Keukeleire, D., 2000. Alterations of the profiles of iso-alpha-acids during beer ageing, marked instability of trans-iso-alphaacids and implications for beer bitterness consistency in relation to tetrahydroiso-alpha-acids.

[9] Journal of the Institute of Brewing, 106, 169-178.

[10] De Clerck, J., 1957. A Textbook of Brewing. Vol. 1, New York; Chapman Hall.

[11] Engan, S., 1969. Some changes in beer flavour during aging. Journal of the Institute of Brewing, 75, 371-376.

[12] European Brewery Convention., 1998. Analytica EBC, 5th Edition, Fachverlag Hans Carl publisher, Nurnberg, pp654
[13] Frank J and Wallen N., 2003. How to design and evaluate research in education, College House: New Jersey

[14] Gora, D., 2003. Taste stability improvement: ESR studies on beer production. Goals- F04. SABMiller Tyskie (Kompania Piwowarska S.A.)

[15] Greenhoff, K., \& Wheeler, R.E., 1981. Analysis of beer carbonyls at the part per billion level by combined liquid chromatography and high pressure liquid chromatography. Journal of the Institute of Brewing, 86, 35-41.

[16] Grimmer, H.R., and Torline, P., 2003. Consistency to the consumer in Institute and Guild of Brewing. Africa Sectionproceedings 9th Brewing Convention. Victoria Falls, Zambia.

[17] Hashimoto, N., 1966. Rep. Res. Lab. Kirin Brewery Co., 9, 1.

[18] Huvaere, K., Andersen, M. L., Olsen, K., Skibsted, L. H., Heyerick, A., \& De Keukeleire, D. 2003. Radicaloid-type oxidative decomposition of beer bittering agents revealed. Chemistry-a European Journal, 9, 4693-4699.

[19] Institue of Brewing and Distillation., 2008. Diploma in brewing 2 revision notes version 1. Jamieson, A. M., \& Van Gheluwe, J. E. A.,1970. Identification of a compound responsible for cardboard flavor in beer. Proceedings of the American Society of Brewing Chemists, 192-197

[20] Kaneda, H., Kano, Y., Kamimura, M., Kawaskishi, S., \& Osawa, T., 1991. A study of beer staling using chemiluminescence analysis. Journal of the Institute of Brewing, 97, 105-109.

[21] Kaneda, H., Kano, Y., Osawa, T., Kawakishi, S., \& Kamada, K., 1989. The role of free radicals in beer oxidation. Journal of the American Society of Brewing Chemists, 47, 49-53.

[22] Lustig, S., Miedaner, H., Narziss, L., \& W., B., 1993. Untersuchungen flu"chtiger aromastoffe bei der bieralterung mittels multidimensionaler gaschromatographie. Proceedings of the European Brewery Convention Congress, $445-452$

[23] Nielson S. S., 2002. Introduction to Chemical Analysis on Foods, Perdue University -West Lafayette, Indiana. CBS Publishers and Distributors, New Delhi India

[24] Palamand, S. R., \& Hardwick, W. A., 1969. Studies on the relative flavor importance of some beer constituents. MBAA Technical Quarterly, 6, 117-128

[25] Parasfevas A and Atinay (2008) Planning Research in Hospitality and Tourism, Elsevier Ltd

[26] Preedy, V.R., 2009. Beer in Health and Disease Prevention. Elsevier Inc.: London.

[27] Punch K.F., 2004. Introduction to Social Research (Qualitative and Quantitative Approaches) Sage Publications, London

[28] SAB Brewing manual, volume 111 -Microbiological methods, August 2002 SAB Beer Division Quality assurance manual

[29] Schaefer R. T., 2006. Sociology -A brief introduction 6th Edition. McGraw Hill

[30] Thum, B., Miedaner, H., Narziss, L., \& Black, W., 1995. Bildung von Alterundscarbonylen - mo"geliche Mechanismen und Bedeutung bei der Bierlagerung. Proceedings of the European Brewery Convention Congress, 491-498. 
[31] Torline, P., and H. Grimmer, H., 2002, Presentation at Miller Brewing Co., Milwaukee, WI: The quest for long shelf life of beer. SAB Ltd., Corporate Technical Center.

[32] Vanderhaegen, B., Neven, H., Daenen, L., Verstrepen, K. J., Verachtert, H., \& Derdelinckx, G., 2004. Furfuryl ethyl ether: Important aging flavor and a new marker for the storage conditions of beer. Journal of Agricultural and Food Chemistry, 52, 1661-1668.
[33] Verbelen, P. J. Mulders, S. V. Saison, D. Laere, S.V. Delvaux, F. and Delvaux, F. R. 2008. Characteristics of high cell density fermentations with different lager yeast strains, J. Inst. Brew., 114: 127-133. 